\title{
GLOBAL REFERENCE ATMOSPHERIC MODELS, INCLUDING THERMOSPHERES, FOR MARS, VENUS AND EARTH
}

\author{
Hilary L. Justh ${ }^{(1)}$, C. G. Justus ${ }^{(2)}$, Vernon W. Keller ${ }^{(1)}$ \\ ${ }^{(1)}$ NASA Marshall Space Flight Center, EV13, Marshall Space Flight Center, AL \\ 35812 (USA), Hilary.L.Justh@nasa.gov, Vernon.Keller@nasa.gov \\ (2) Morgan Research Corporation, 4811-A Bradford Drive, Huntsville, AL 35805 - \\ 1948 (USA), Jere.Justus@.nasa.gov
}

\begin{abstract}
Marshall Space Flight Center's Natural Environments Branch has developed Global Reference Atmospheric Models (GRAMs) for Mars, Venus, Earth, and other solar system destinations. Mars-GRAM has been widely used for engineering applications including systems design, performance analysis, and operations planning for aerobraking, entry descent and landing, and aerocapture. Preliminary results are presented, comparing Mars-GRAM with measurements from Mars Reconnaissance Orbiter during its aerobraking in Mars' thermosphere. Venus-GRAM is based on the COSPAR Venus International Reference Atmosphere (VIRA), and is suitable for similar engineering applications in the thermosphere or other altitude regions of the atmosphere of Venus. Until recently, the thermosphere in Earth-GRAM has been represented by the Marshall Engineering Thermosphere (MET) model. Earth-GRAM has recently been revised. In addition to including an updated version of MET, it now includes an option to use the Naval Research Laboratory Mass Spectrometer Incoherent Scatter Radar Extended Model (NRLMSISE-00) as an alternate thermospheric model. Some characteristics and results from Venus-GRAM and Earth-GRAM thermospheres are also presented.
\end{abstract}




\title{
GLOBAL REFERENCE ATMOSPHERIC MODELS, INCLUDING THERMOSPHERES, FOR MARS, VENUS AND EARTH
}

\author{
Hilary L. Justh ${ }^{1}$ \\ NASA, Marshall Space Flight Center, AL, 35812 \\ C. G. Justus ${ }^{2}$ \\ Morgan Research Corporation, Huntsville, AL, 35805-1948 \\ and \\ Vernon W. Keller ${ }^{3}$ \\ NASA, Marshall Space Flight Center, AL, 35812
}

\begin{abstract}
Marshall Space Flight Center's Natural Environments Branch has developed Global Reference Atmospheric Models (GRAMs) for Mars, Venus, Earth, and other solar system destinations. Mars-GRAM has been widely used for engineering applications including systems design, performance analysis, and operations planning for aerobraking, entry descent and landing, and aerocapture. Preliminary results are presented, comparing MarsGRAM with measurements from Mars Reconnaissance Orbiter (MRO) during its aerobraking in Mars' thermosphere. Venus-GRAM is based on the Committee on Space Research (COSPAR) Venus International Reference Atmosphere (VIRA), and is suitable for similar engineering applications in the thermosphere or other altitude regions of the atmosphere of Venus. Until recently, the thermosphere in Earth-GRAM has been represented by the Marshall Engineering Thermosphere (MET) model. Earth-GRAM has recently been revised. In addition to including an updated version of MET, it now includes an option to use the Naval Research Laboratory Mass Spectrometer Incoherent Scatter Radar Extended Model (NRLMSISE-00) as an alternate thermospheric model. Some characteristics and results from Venus-GRAM and Earth-GRAM thermospheres are also presented.
\end{abstract}

\section{Introduction}

$\mathrm{M}$ arshall Space Flight Center's Natural Environments Branch has developed Global Reference Atmospheric Models (GRAMs) for Mars, Venus, Earth, and other Solar system destinations ${ }^{1-4}$. Mars-GRAM has been widely used for engineering applications including systems design, performance analysis, and operations planning for aerobraking, entry descent and landing, and aerocapture. The thermosphere section of Mars-GRAM is based on output data sets from the University of Michigan Mars Thermospheric General Circulation Model (MTGCM) ${ }^{5}$. Venus-GRAM is based on the Committee on Space Research (COSPAR) Venus International Reference Atmosphere (VIRA) ${ }^{6}$, and is suitable for similar engineering applications in the thermosphere or other altitude regions of the atmosphere of Venus. For Venus-GRAM, the thermospheric section has been extended to higher altitudes by using a simple constant-temperature, diffusive separation model. Until recently, the thermosphere in Earth-GRAM has been represented by the Marshall Engineering Thermosphere (MET) model ${ }^{4}$. Earth-GRAM has recently been revised. In addition to including an updated version of MET, it now includes an option to use the Naval Research Laboratory Mass Spectrometer Incoherent Scatter (MSIS) Radar Extended Model (NRLMSISE-00) ${ }^{7}$ as an alternate thermospheric model.

\footnotetext{
${ }^{1}$ Flight Vehicle Atmospheric Environments, Natural Environments Branch, EV13.

${ }^{2}$ Senior Principal Scientist, Natural Environments Branch, EV13/Morgan Research Corporation, Senior Member.

${ }^{3}$ Flight Vehicle Atmospheric Environments, Natural Environments Branch, EV13, Member.
} 
As illustrated by Fig. 1, thermospheric densities for Venus, Earth, and Mars are quite similar, compared to thermospheric densities for other planets, exemplified by Titan and Neptune profiles in this figure.

Preliminary results are presented, comparing Mars-GRAM thermospheric densities with accelerometer-measured density from Mars Reconnaissance Orbiter (MRO) during its aerobraking in Mars' thermosphere. Some characteristics and results from Venus-GRAM and EarthGRAM thermospheres are also presented.

\section{Mars-GRAM Thermosphere}

A major application for the thermospheric part of Mars-GRAM has been in support of aerobraking planning and operations at Mars. Aerobraking involves multi-orbit passes through the atmosphere, using density-drag to gradually circularize a high-eccentricity (captured) orbit into a more circular operations (science) orbit. This contrasts with aerocapture, which uses a single drag pass through the atmosphere to get into a captured orbit from interplanetary transfer orbit. Typical altitudes and atmospheric densities for aerobraking and aerocapture at Mars, or other destinations, are shown in Fig. 1.

Mars Reconnaissance Orbiter (MRO) is currently performing aerobraking operations at Mars. Figure 2 shows preliminary results comparing MarsGRAM density with MRO accelerometerderived density ${ }^{8}$. A height offset of $+5 \mathrm{~km}$ was used for Mars-GRAM. The range of altitudes and latitudes encountered during this observation period are given in the figure labels. Since MRO is in a Sunsynchronous orbit, each periapsis pass occurs at the same local time, but at a different longitude. The large observed orbit-to-orbit variation in periapsis density (about $21 \%$ standard deviation in Fig. 2) is due to longitude-and-altitude-varying waves near periapsis (a possible combination of stationary or traveling planetary-scale waves plus local, large-scale gravity waves). Mars-GRAM values used for the ratios in Fig. 2 are for the mean atmosphere only (not including wave-perturbation effects). 


\section{Venus-GRAM Thermosphere}

Below $250 \mathrm{~km}$ altitude, Venus-GRAM is based on the Venus International Reference Atmosphere (VIRA) ${ }^{6}$ model. The Venus-GRAM thermosphere has been extended to an altitude of $1000 \mathrm{~km}$, by a model based on the following assumptions:

- VIRA conditions and constituents at $250 \mathrm{~km}$ are used as lower boundary values

- Constant (exospheric) temperature is assumed above $250 \mathrm{~km}$ (exospheric temperature = local VIRA temperature at $250 \mathrm{~km}$ )

- Hydrostatic conditions are computed separately for each constituent (diffusive separation)

- Total pressure is computed from constituent partial pressures

- Mass density is computed from constituent number densities

Figure 3 shows a plot of typical VenusGRAM exospheric temperature versus time of day, together with altitude-time contours of Venus-GRAM thermospheric density. As expected, exospheric temperature is highest (about $300 \mathrm{~K}$ ) for a few hours on either side of solar noon. Normally, hydrostatic conditions mean that densities at high altitudes are larger for higher exospheric temperatures (density increases as the entire atmospheric column expands, because of larger temperatures). However, Fig. 3 shows that, above about $300 \mathrm{~km}$ altitude, density is at a relative minimum near solar noon, despite the higher values of exospheric temperature at this time of day. This apparent anomaly can be explained from information in Fig. 4 and Fig. 5, which show (respectively) contours of mean molecular weight (M) and density scale height $(\mathrm{H})$ versus altitude and local time. $H$ is proportional to $T / M$, where $T$ is temperature. Higher exospheric temperature near noon (Fig. 3) would tend to make $\mathrm{H}$ larger near this time of day. However, higher values of $M$ near noon (Fig. 4) would tend to make $\mathrm{H}$ smaller near this time of day. For conditions of Fig. 3 Fig. 5, the $M$ effect dominates, making $H$ smaller near noon (Fig. 5). Since density varies with altitude $\mathrm{z}$ as $\operatorname{Exp}(-\mathrm{z} / \mathrm{H})$, smaller $H$ near noon means that density falls off more rapidly near noon than in morning or afternoon. Hence smaller density values are seen near noon above about $300 \mathrm{~km}$ in Fig. 3.

\section{Earth-GRAM Thermosphere}

The thermosphere in Earth-GRAM has been represented by the Marshall Engineering Thermosphere (MET) model ${ }^{4}$. For an anticipated release in late 2006, Earth-GRAM has been revised, to including an updated version of MET, plus an option to use the Naval Research

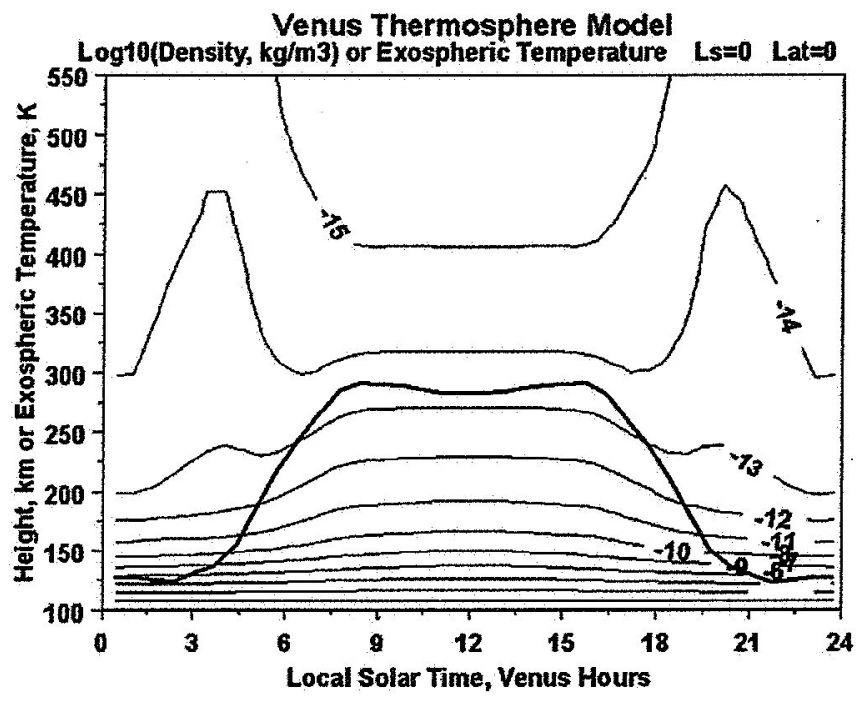

Figure 3. Contours of Venus thermospheric density versus altitude and time of day, and a plot of exospheric temperature (un-numbered line) versus time of day, at Latitude $=0, L s=0$ (Spring equinox). Density contours are labeled in units of $\log$ base-10 of density in $\mathrm{kg} / \mathrm{m}^{3}$.

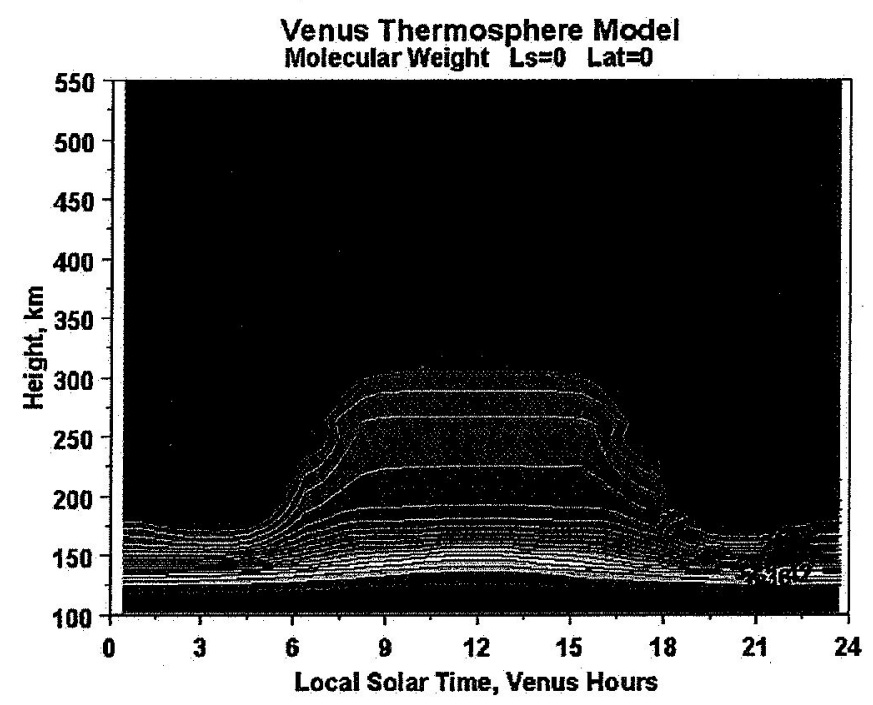

Figure 4. Contours on Venus mean molecular weight $(M)$ versus altitude and time of day, at same conditions as in Figure 3. 
Laboratory Mass Spectrometer Incoherent Scatter (MSIS) Radar Extended Model (NRLMSISE-00) $^{7}$ as an alternate thermospheric model.

A sample comparison of MET and MSIS density values is given in Fig. 6, which plots contours of MET/MSIS ratio versus altitude and latitude for January at 13 hours local time, for solar activity conditions given in the figure caption. Figure 6 shows MET/MSIS density ratios near 1 , except at high northern (winter) latitudes greater than about 60 degrees, and altitudes either above about 600 $\mathrm{km}$ or below about $150 \mathrm{~km}$.

\section{Acknowledgments}

The authors gratefully acknowledge support from MSFC's In-Space Propulsion (ISP) program and the NASA Engineering Safety Center (NESC). Particular thanks go to Bonnie James (MSFC), Manager of Aerocapture Technology, Michelle Munk (MSFC), Lead Systems Engineer for Aerocapture Technology, and Melody Herrmann (MSFC), Manager of Technology Planning and Systems Analysis.

\section{References}

${ }^{1}$ Duvall, A. L. Justus, C. G., and Keller, V. W., "Global Reference Atmospheric Models for Aeroassist Applications," 3rd International Planetary Probe Workshop, Anavyssos, Attiki, Greece, 27 June 2005 - 01 July 2005.

${ }^{2}$ Justus, C. G., Duvall, A. L., and Keller, V. W., "Atmospheric Models for Mars Aerocapture," 41st AIAA/ASME/SAE/ASEE Joint Propulsion Conference \& Exhibit, 11 - 13 July, 2005, Tucson, AZ.

${ }^{3}$ Justus, C. G., Duvall, A. L, and Keller, V. W., "Mars Aerocapture and Validation of Mars Global Reference Atmospheric Model with Thermal Emission Spectrometer Data," 53rd Joint Army-Navy-NASA-Air Force (JANNAF) Propulsion Meeting, 5 - 8 December, 2005, Monterey, CA.

${ }^{4}$ Justus, C. G., Duvall, A. L., and Keller, V. W., "Trace Constituent Updates in the Marshall Engineering Thermosphere and Global Reference Atmospheric Model," Advances in Space Research (to be published).

${ }^{5}$ Bougher, S. W., "Comparative Thermospheres: Venus and Mars," Advances in Space Research, Vol. 15, No. 4, 1995; pp. 21-45.

${ }^{6}$ Kliore, A. J., Moroz, V. I., and Keating, G. M. (editors), "The Venus International Reference Atmosphere," Advances in Space Research, Vol. 5, No. 11, 1985, pp. 1-304.

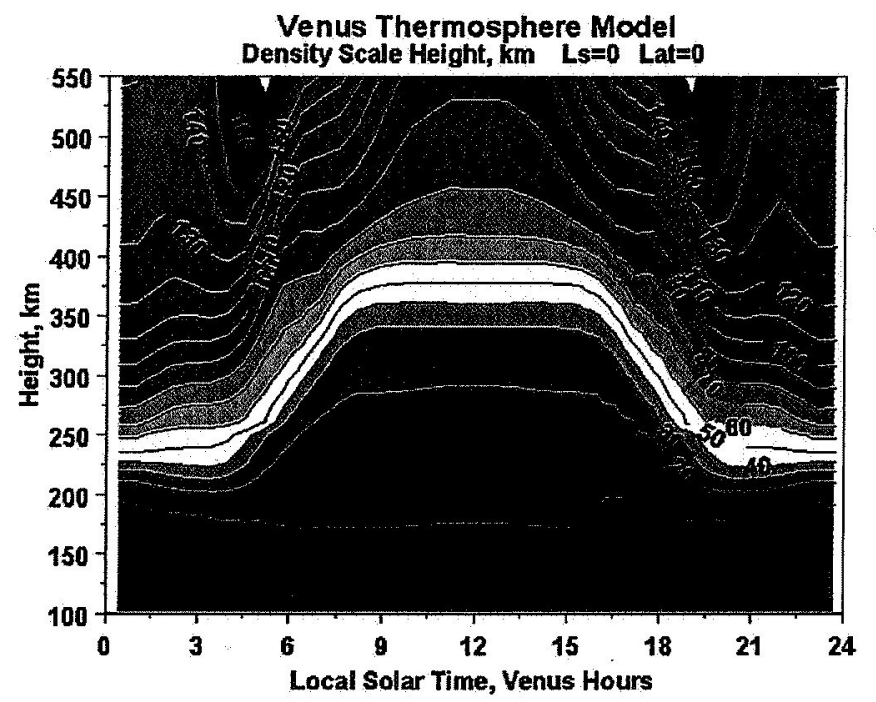

Figure 5. Contours on Venus density scale height $(\mathbf{H})$ versus altitude and time of day, at same conditions as in Figure 3.

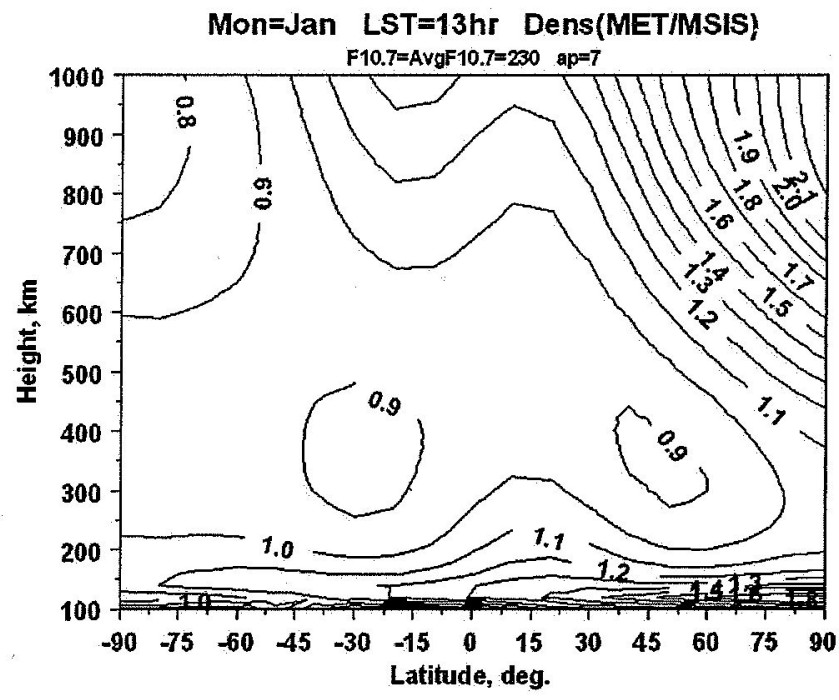

Figure 6. Comparison of Earth-GRAM thermospheric density from Marshall Engineering Thermosphere (MET) model and MSIS model (contours of MET/MSIS ratio) versus altitude and latitude, for January, local time $=13$ hours, and solar activity $F 10.7=\operatorname{Avg}(F 10.7)=230$, and ap $=7$. 
${ }^{7}$ Hedin, A. E., "Extension of the MSIS Thermosphere Model into the Middle and Lower Atmosphere," Journal of Geophysical Research, Vol. 96, 1991, p. 1159.

${ }^{8}$ Tolson, R. H., Keating, G. M., Zurek, R. W., Bougher, S. W., and Justus, J., “Application of MGS and MO Aerobraking Accelerometer Data to Atmospheric Modeling," ALAAVAAS Astrodynamics Specialist Conference \& Exhibit, 21 - 24 August, 2006, Keystone, $\mathrm{CO}$. 

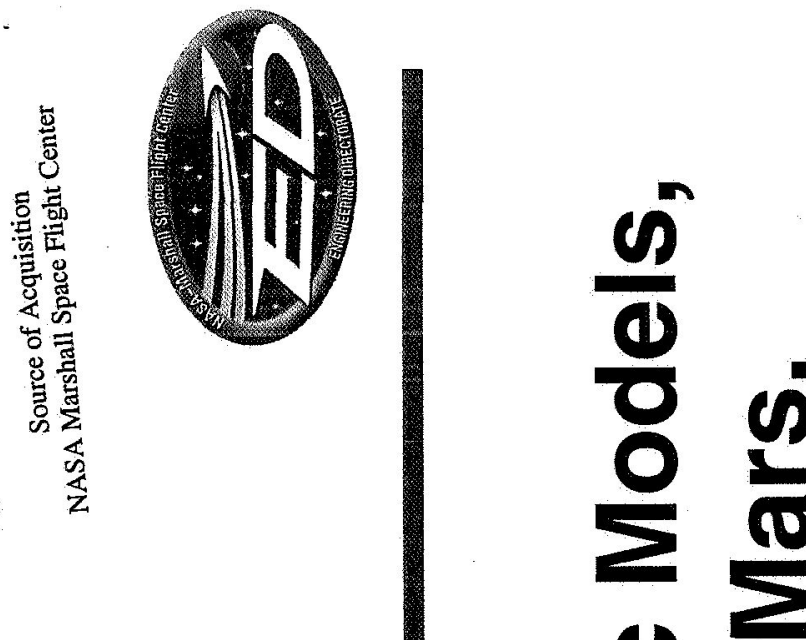

는 는 은

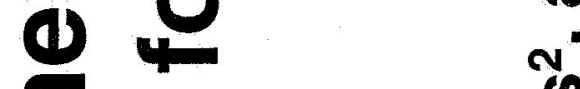

웜 $\frac{1}{0}$

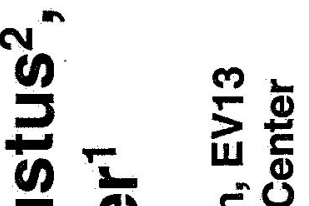

동 홍

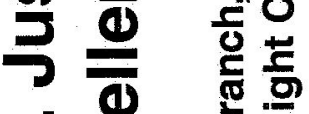

응 츰

(5) 它茾 8

$\longrightarrow \quad \begin{aligned} & 0 \\ & 0\end{aligned}$

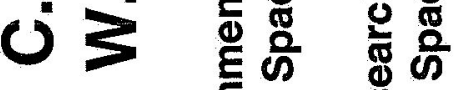

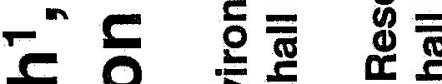

$\frac{8}{\frac{10}{0}}$

(a) 0

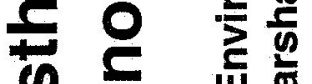

(6) 5

ด E

돈

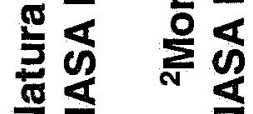

(a) 019

(4) 1

(d) 0 I

a 20

6020

$>$

$+$

$\sum_{2} \frac{1}{z}$

토

(b)

E 8

ㄴ.

$\Phi$

5

$3 \%$

$+2$

은

10

(1)

온

(n)

0 क

03

$E 3$

$\sum 1$

$8 N$

e

(5)

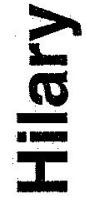

050

( ) 15

(i) $=$

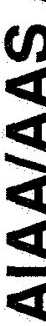




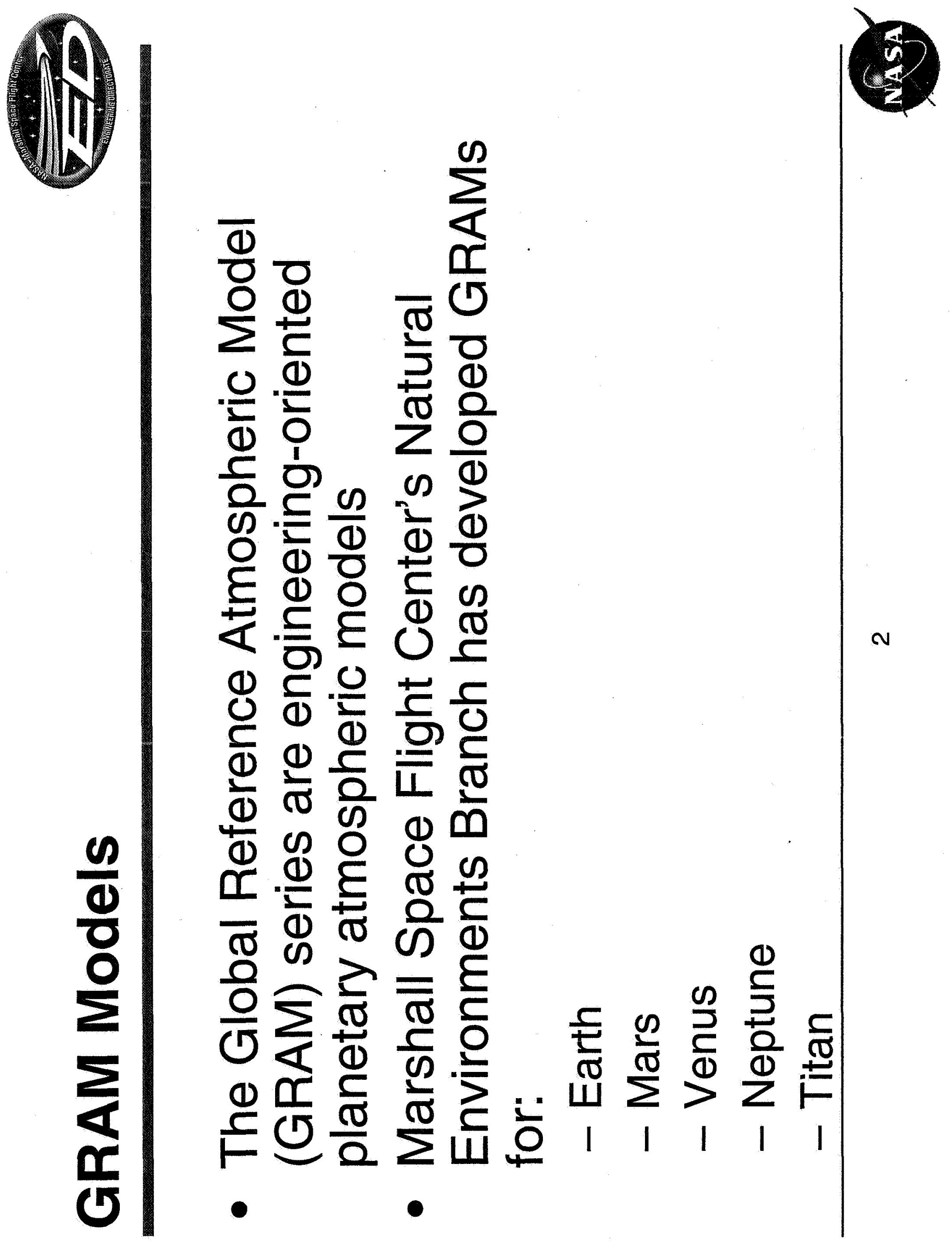




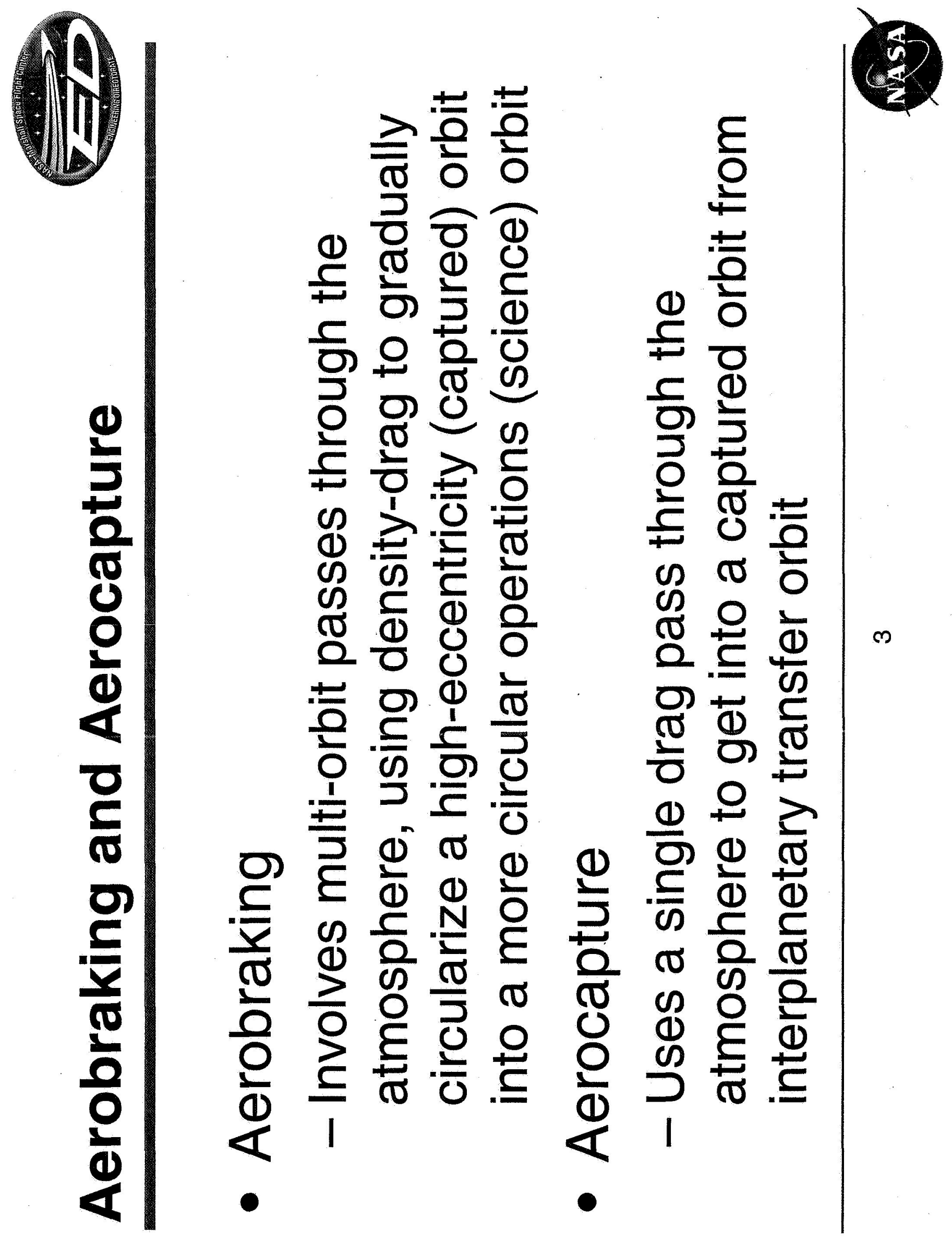




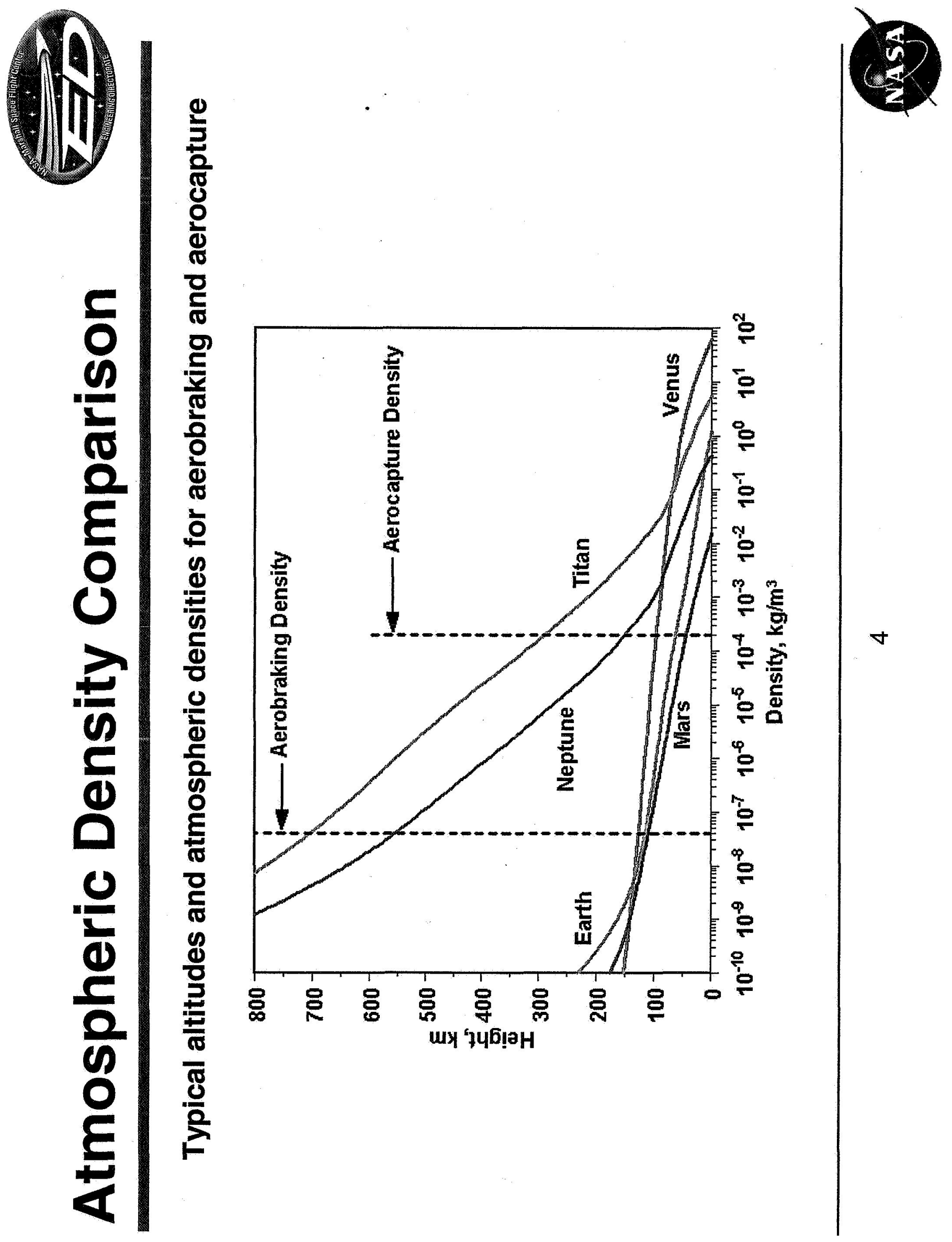




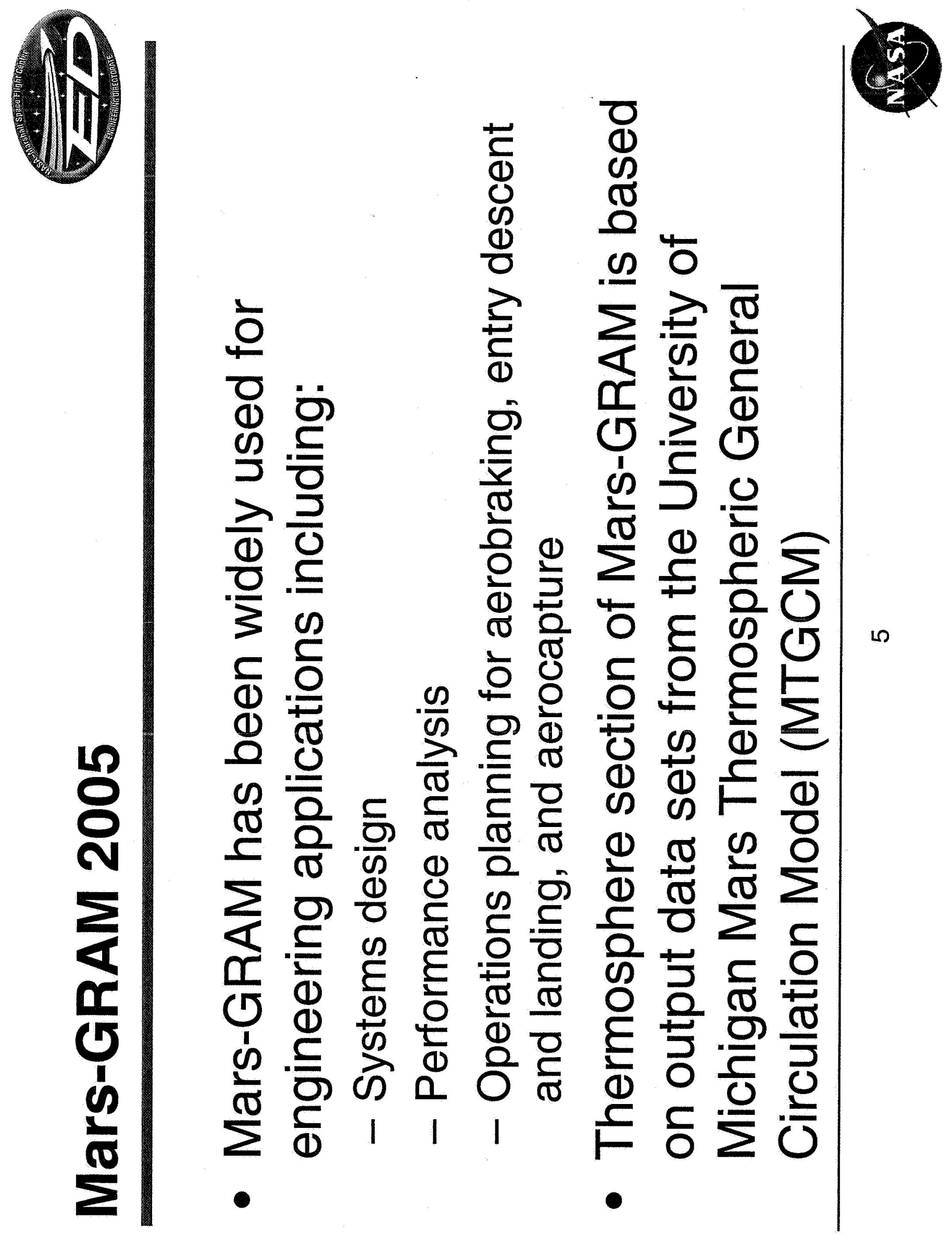




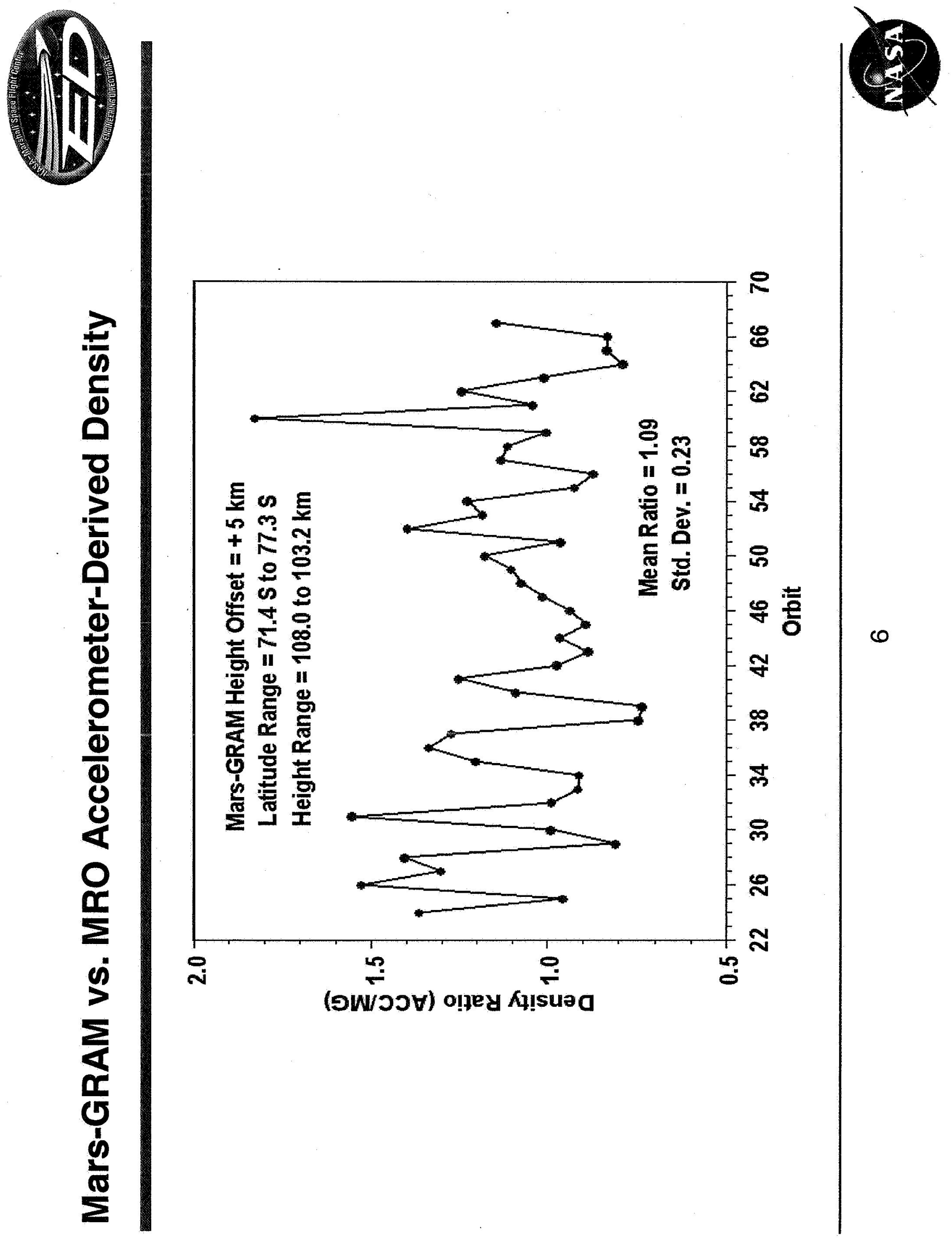




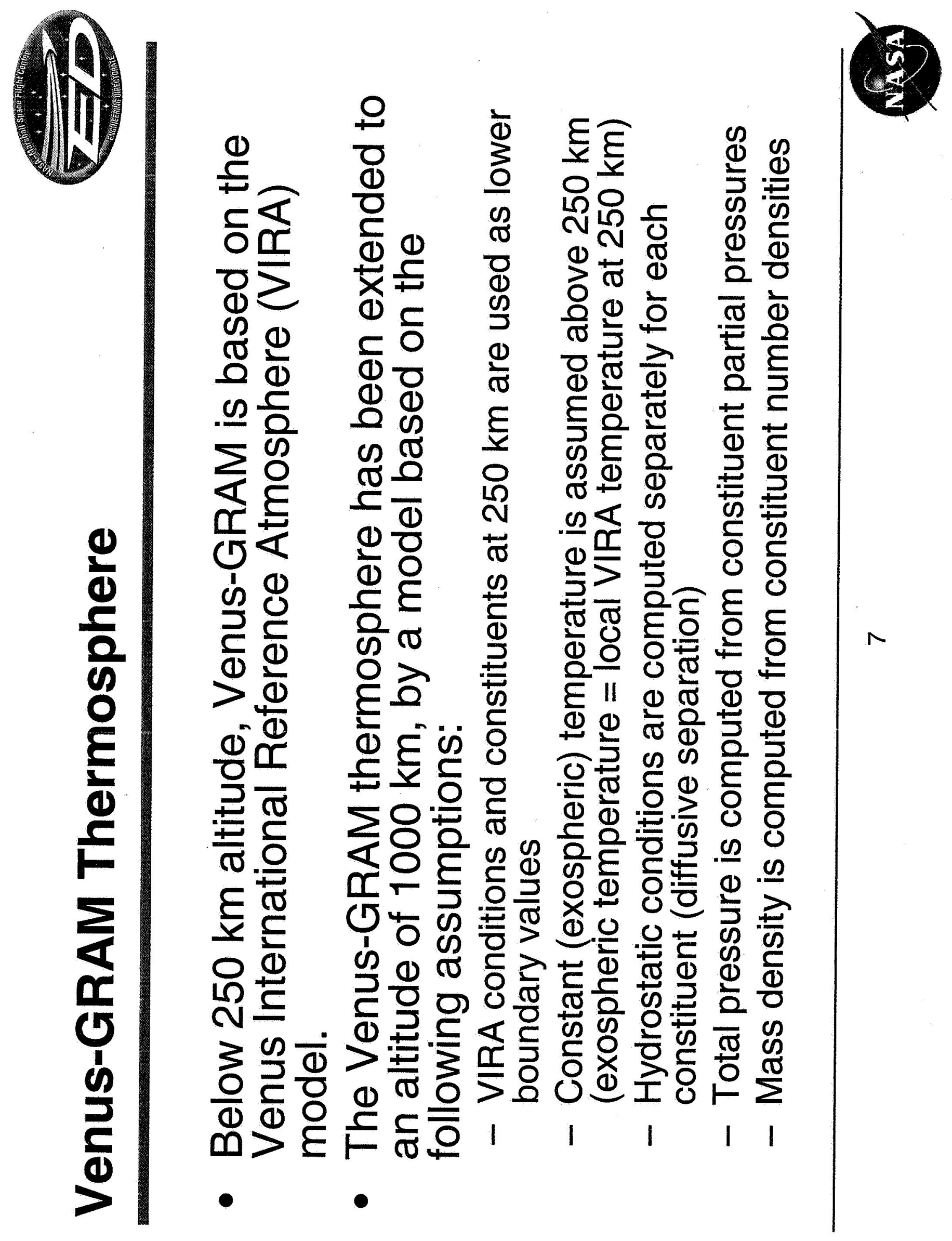




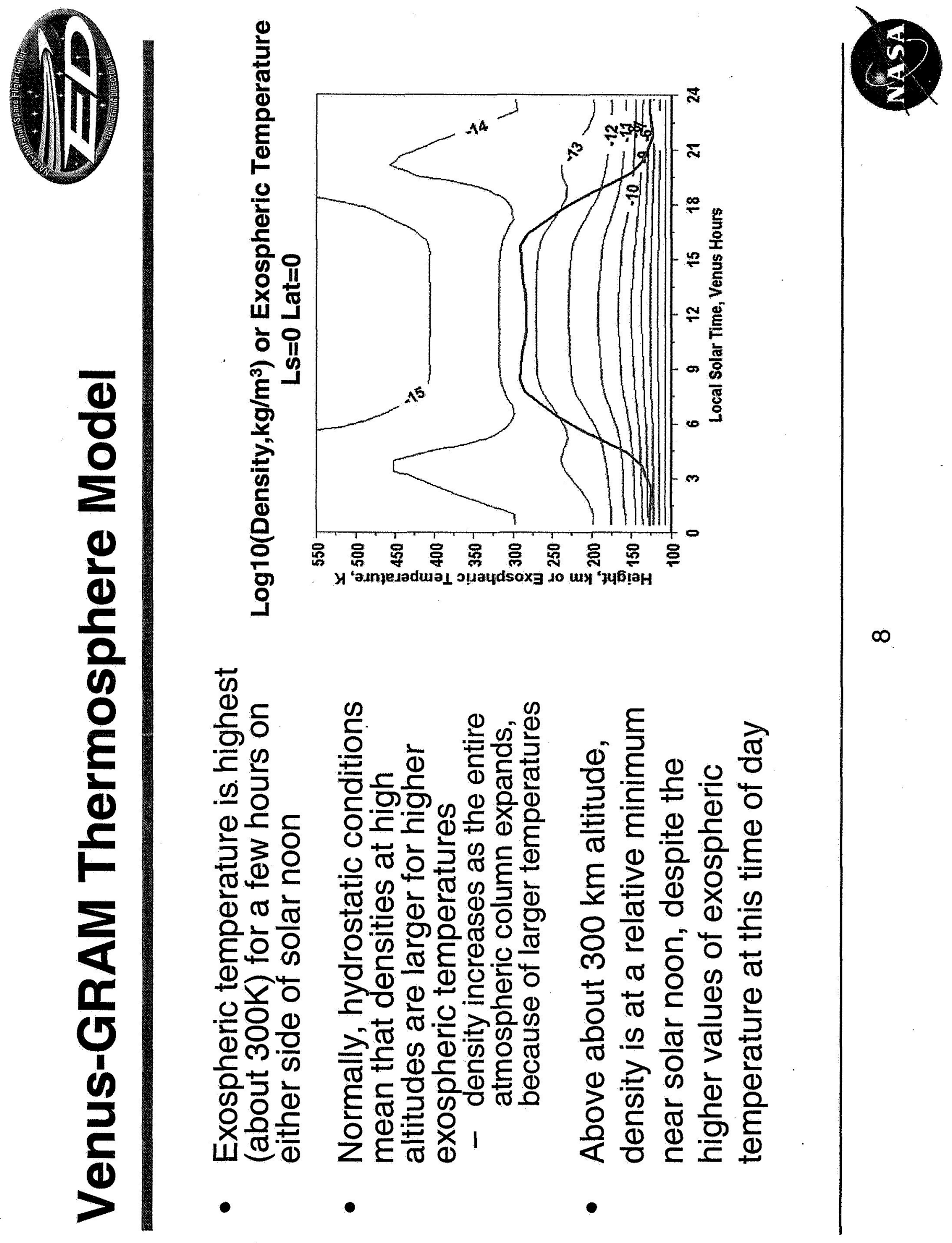




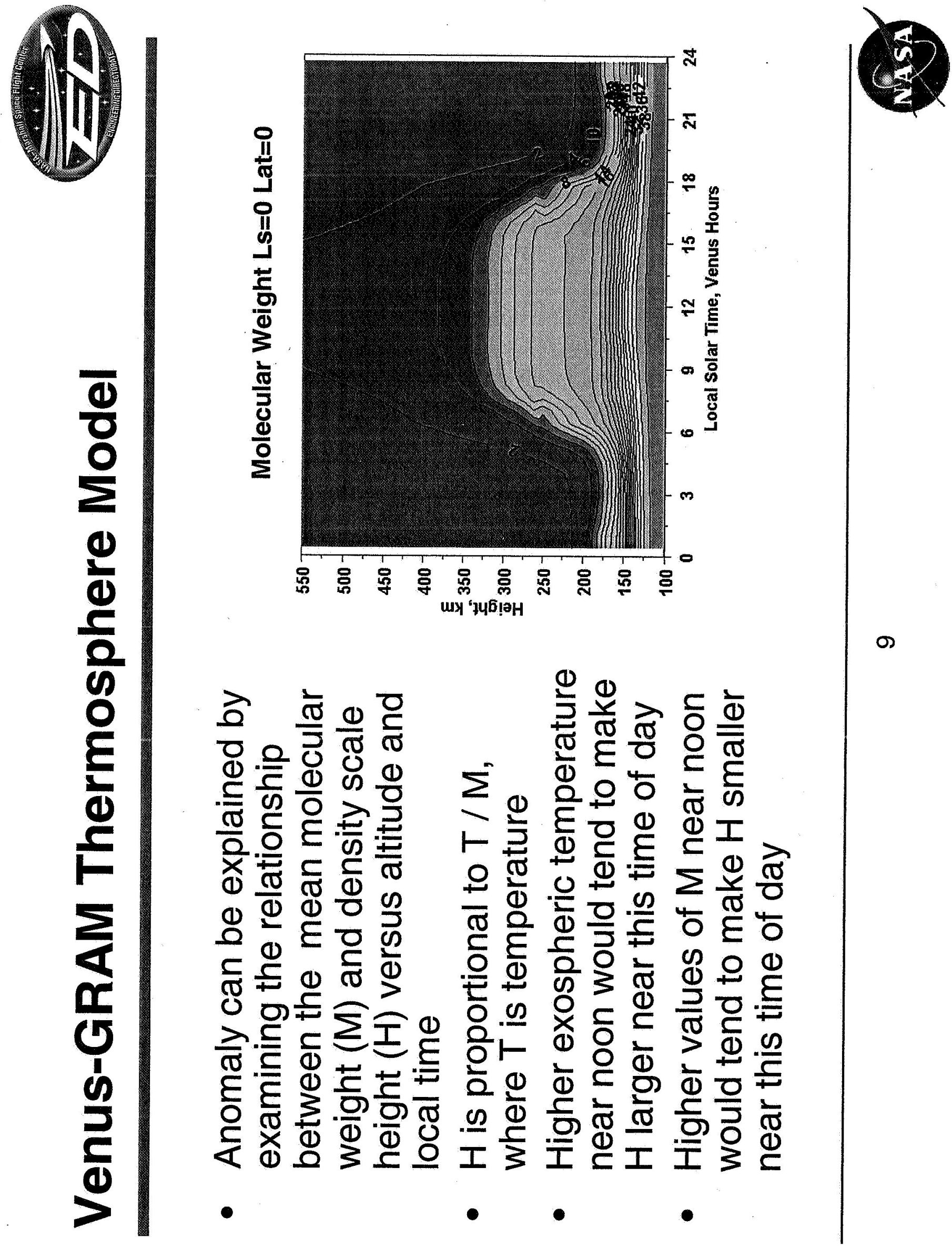




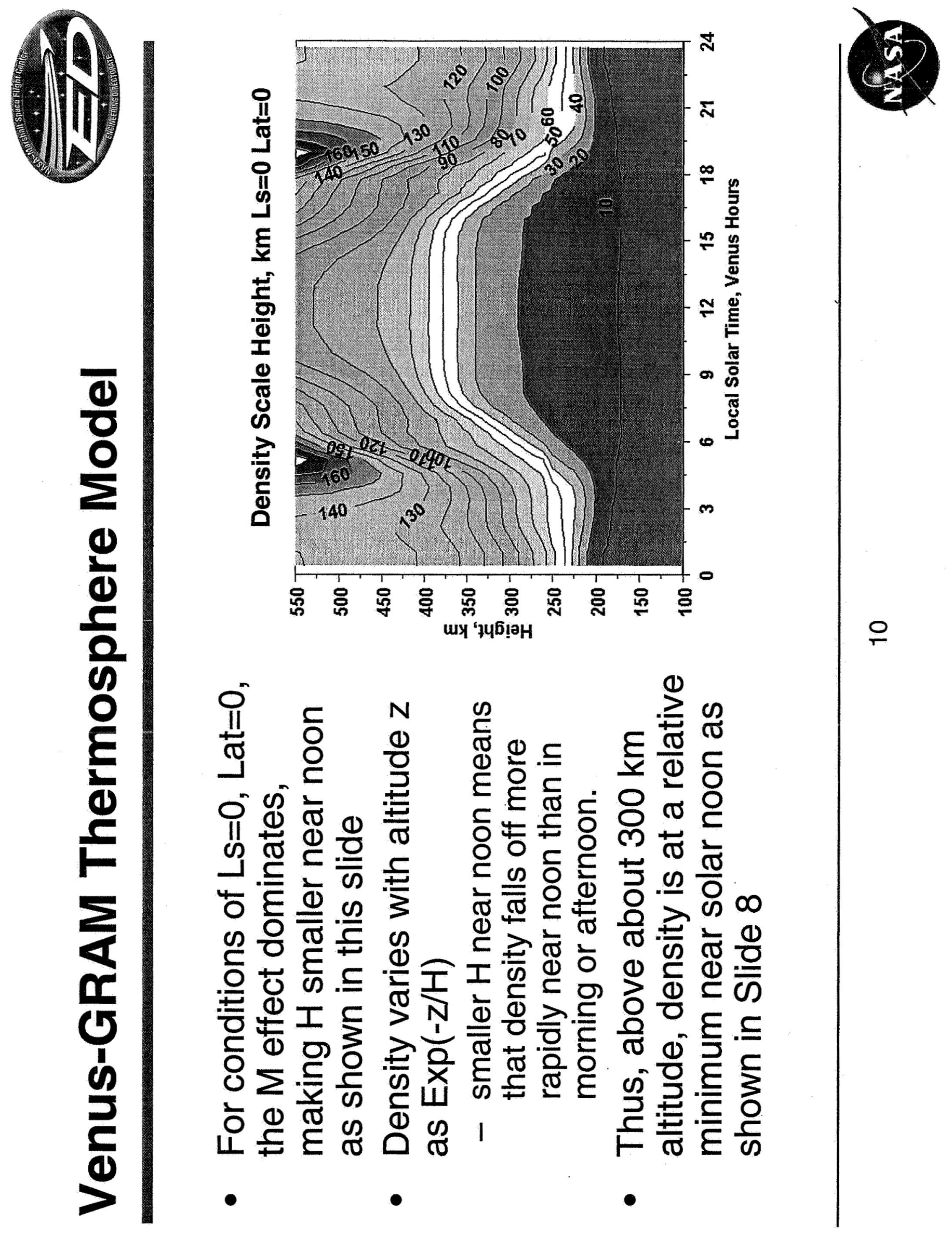




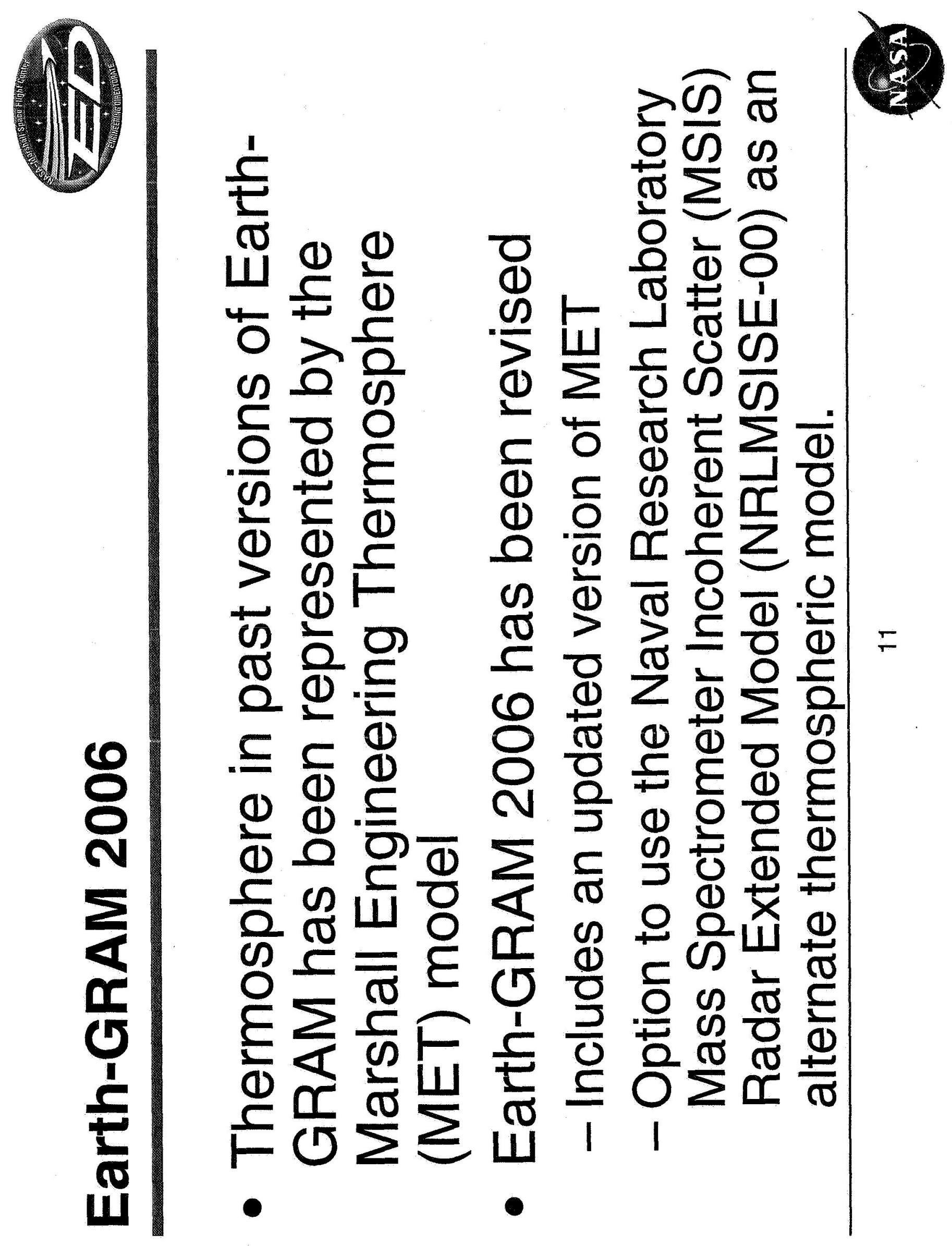




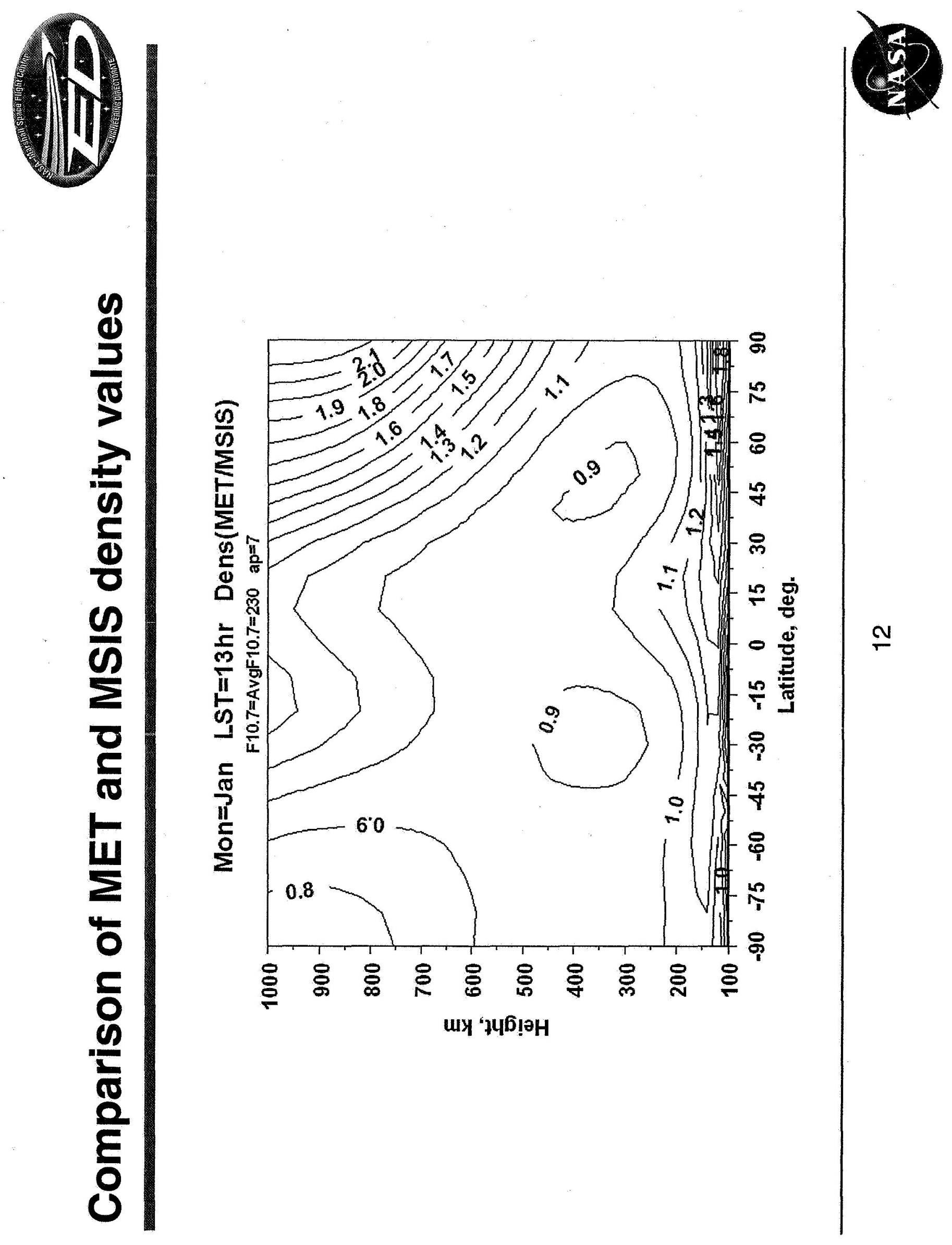

